\title{
Assessment of Risk Factors in MDR TB Patients. The Reasons behind Their Admission to DOTS plus Centres. Will They Pass Through?
}

\author{
V.P. Amudha1, G. Sucilathangam ${ }^{2 *}$, N. Dilip Jaivanth ${ }^{3}$ and C. Revathy ${ }^{3}$ \\ ${ }^{1}$ Department of Microbiology, K.A.P. Viswanatham Government Medical College, \\ Tiruchirappalli - 620001, Tamil Nadu, India \\ ${ }^{2}$ Department of Microbiology, Government Theni Medical College, Theni - 625512, \\ Tamil Nadu, India \\ ${ }^{3}$ Department of Microbiology, Tirunelveli Medical College, Tirunelveli - 627011 , \\ Tamil Nadu, India \\ *Corresponding author
}

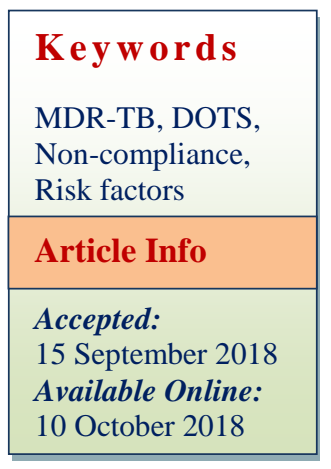

A B S T R A C T

\section{Introduction}

Good adherence to Tuberculosis (TB) treatment is crucial to cure patients, to limit the development of drug resistance and to reduce TB transmission in the community. For years, World Health Organization (WHO, 2006) has been recommending the 
administration of drugs through directly observed therapy short course (DOTS) as a part of the control strategy.

Irregular, incomplete and inadequate treatment is the most common means of acquiring drug resistant organism. The current threat is multidrug-resistant tuberculosis (MDR- TB) due to the emergence of strains resistant to the two most potent anti-tuberculosis drugs Isoniazid (H) and Rifampicin (R) (Sharma SK, 2004) According to the 2008 estimates, there were 440.000 cases and 150.000 deaths of MDR-TB globally. (WHO, 2010) Due to the emergence of MDRTB, the WHO developed a directly observed therapy short course (DOTS) Plus strategy in 2000. (WHO, 2011) This strategy aims at ensuring correct identification and proper management of MDR-TB patients.

In 2008, the WHO reported that the global weighted mean rate of MDR was $2.9 \%$ among new patients and $15.3 \%$ among previously treated patients. (WHO, 2008) In addition, gender, age, poor living conditions, the presence of a cavity on the patient's chest, unemployment, poor medical management of the patient's treatment, lack of directly observed treatment, abandonment of treatment, seeking initial care at a nonprofessional health care facility and limited or interrupted drug supplies, association with HIV/AIDS etc are found to be associated with MDR-TB. (Songhua C et al., 2013)

The risk factors that had led to the development of multidrug resistance will persist and may pave the way for development of Extensive Drug resistance (XDR-TB) which is a forthcoming serious threat. XDRTB is resistant to these first line antituberculous agents, as well as to at least one Fluoroquinolone and at least one injectable agent. This phenotype emerges from MDRTB, with the acquisition of further drug resistance mutations, and was first described in the United States followed by the Tugela Ferry outbreak. (Gandhi NR et al., 2006)With this background, the present study was conducted in DOTS plus centre, Tirunelveli Medical College Hospital to explore the risk factors for development of drug resistance.

\section{Materials and Methods}

This study was conducted at DOTS PLUS centre, Department of Thoracic Medicine, Tirunelveli Medical College which covers the three districts of Tirunelveli, Tuticorin and Kanyakumari for the period of 6 months. The study protocol was carried out after approval by the Institutional Scientific and Ethics Committee.

\section{Study population}

\section{Inclusion criteria}

Men and women > 19 years of age who are newly started on Category IV anti-TB treatment at the DOTS PLUS centre.

Men and women $>19$ years of age who are already on Category IV anti-TB treatment, attending the DOTS PLUS centre for follow up.

\section{Exclusion criteria}

Patients $<20$ years of age

Patients too ill to be interviewed

Unwilling to participate in the study

\section{Study Design}

A questionnaire-based case control study amongst 50 MDR-TB cases and 25 Non-MDR TB controls was conducted. The source of control constituted hospital controls who are free from MDR tuberculosis i.e. sputum positive tuberculosis patients who had 
undergone DOTS treatment for at least five months with negative findings on sputum microscopy. Information was collected from cases and control on a wide range of potential host related, environmental and health service related risk factors for MDR TB. The patients were interviewed using semi constructed questionnaire developed to ascertain potential risk factors. Additionally, information related to Diabetes mellitus and HIV status, was also collected.

\section{Statistical analysis}

For comparison of categorical variables, significance testing is done by Pearson chi square test and using 2-sided Fisher's exact test as appropriate. Associations between selected factors are estimated by computing odds ratios (ORs) and their 95\% confidence intervals (CIs) from an unconditional logistic regression model. The criterion for significance is set at $\mathrm{P}<0.05$ based on a twosided test.

\section{Results and Discussion}

\section{Socio-demographic characteristics}

A total of 50 patients who were newly started on Category IV anti-TB treatment or came for follow up at the DOTS PLUS centre, Department Of Thoracic Medicine, Tirunelveli Medical College Hospital were analysed, of which 30 were males and 20 were females. Age distribution data shows that maximum number of cases was seen in age group above 50 (Figure 1). Among the 50 cases, 5 cases had a secondary or more level of education (10\%). 45 patients $(90 \%)$ had less than secondary level of education. Patients who resided within the Tirunelveli Corporation limits were taken as urban population and the others as rural population. $86 \%$ of the cases from the rural areas are under treatment for MDR-TB. The type of occupation among the study group is tabulated. Majority of them (48\%) were workers and daily labourers (Table 1).

\section{TB treatment adherence status (Table 2)}

\section{Distance}

It was found that distance is a main factor for non-adherence. About $70 \%$ (35) of MDR TB and $60 \%$ (15) of Non MDR TB patients have to walk a long distance to avail the medicine (OR 1.5556; 95\% CI 0.5705-4.2414). Significant association have been found between non-adherence and distance.

\section{Side effects}

Among the MDR-TB patients, 44\% (22) had side effects during TB treatment in comparison to $0 \%$ (0) of the non-MDR group (OR 40.2632; 95\% CI 2.3221-698.1242). Statistical analysis showed that there is a significant association between side effects and adherence to the TB treatment.

\section{Migration}

Among the MDR-TB patients, 58\% (29) migrate to distant places for work or other cause in comparison to $60 \%$ (15) of the nonMDR group (OR 0.9206; 95\% CI 0.4092.887) thus disrupting the treatment. This leads to the development of drug resistant TB ( $\mathrm{p}$ value $=0.868$ )

\section{Alcoholism}

Out of 30 male patients of MDR TB and 19 male patients of Non MDR TB, 19 Patients of MDR TB are alcoholic in comparison to 9 patients of Non MDR TB (OR 3.4286; 95\% CI 1.0304-11.4078). During statistical analysis a strong association is shown between alcoholism and risk of becoming ill with MDR-TB ( $p$ value=0.0445). The finding of 
this study showed that those with the habit of alcoholism are more likely to become ill with MDR-TB in comparison to those who are nonsmokers.

\section{Knowledge on MDR TB and DOTS PLUS}

Out of 50 patients of MDR TB and 25 patients of Non MDR TB, 19 Patients of MDR TB do not have sufficient knowledge on MDR TB treatment and duration in comparison to 16 patients of Non MDR TB (OR 2.9006; 95\% CI 1.0708-7.8572). Inadequate knowledge leads to the discontinuation of treatment paving way for the development of DR TB.

\section{Missed doses of anti-TB drugs during} intensive phase of previous treatment

Of 50 MDR-TB who had history of previous TB treatment, $90 \%$ of MDR-TB patients missed dose of ATT during intensive phase. $10 \%$ of MDR-TB cases patients didn't miss anti-TB treatment during intensive phase of previous treatment.

\section{Previous history of TB treatment}

Among the MDR-TB patients, 94\% (47) have previously been treated for TB in comparison to $0 \%$ (0) of the non-MDR group (OR 692.1429; $95 \%$ CI 34.3891-13930.6417). Similarly, during multivariate analysis by Pearson chi square test strong association is shown between previous history of TB treatment and risk of becoming ill with MDRTB ( $p$ value $=<0.0001$ ). The finding of this study showed that those with history of previous $\mathrm{TB}$ treatment are more likely to become ill with MDR-TB in comparison to those who had no previous history of $\mathrm{TB}$ treatment.

\section{Smoking}

Out of 30 male patients of MDR TB and 19 male patients of Non MDR TB, 26 Patients of MDR TB are smokers in comparison to 11 patients of Non MDR TB (OR 4.7273; 95\% CI 1.1751-19, 0168). During statistical analysis a strong association is shown between smoking and risk of becoming ill with MDRTB ( $p$ value $=0.0287$ ). The finding of this study showed that those with the habit of smoking are more likely to become ill with MDR-TB in comparison to those who are nonsmokers.

\section{Diabetes mellitus}

Among the MDR-TB patients, 15 patients have previous history of diabetes in comparison to 7 patients of the non-MDR group (OR 1.1020; 95\% CI 0.38103.1876).But analysis by Pearson chi square test shows that the development of MDR TB and previous history of diabetes mellitus is not significant $(\mathrm{p}$ value $=0.8577)$.

Fig.1

\begin{tabular}{|l}
\hline AGE WISE DISTRIBUTION \\
\\
\\
$20-24$ \\
$25-29$ \\
$30-34$ \\
$35-39$ \\
$40-44$ \\
\hline
\end{tabular}


Table.1 Association of socio-demographic factors with MDR-TB

\begin{tabular}{|c|c|c|c|c|c|c|}
\hline \multirow[t]{2}{*}{ Variables } & \multicolumn{2}{|c|}{$\begin{array}{c}\text { MDR TB } \\
\text { CASES } \\
\mathbf{N}=\mathbf{5 0}\end{array}$} & \multicolumn{2}{|c|}{$\begin{array}{l}\text { NON-MDR TB } \\
\text { CASES N= 25 } \\
\text { (CONTROLS) }\end{array}$} & \multirow{2}{*}{$\begin{array}{c}\begin{array}{c}\text { TOTAL } \\
\text { N=75 }\end{array} \\
\text { N }\end{array}$} & \multirow{2}{*}{$\begin{array}{c}\text { PERCENTAGE } \\
\%\end{array}$} \\
\hline & $\mathrm{N}$ & $\%$ & $\mathrm{~N}$ & $\%$ & & \\
\hline \multicolumn{7}{|l|}{ Age in years } \\
\hline$\leq \mathbf{3 0}$ & 4 & $8 \%$ & 1 & $4 \%$ & 5 & 6.65 \\
\hline$>30$ & 46 & $92 \%$ & 24 & $96 \%$ & 70 & 93.1 \\
\hline \multicolumn{7}{|l|}{ Gender } \\
\hline Male & 30 & 60 & 19 & 76 & 49 & 65.17 \\
\hline Female & 20 & 40 & 6 & 24 & 26 & 34.58 \\
\hline \multicolumn{7}{|c|}{ Marital status } \\
\hline single & 13 & 26 & 5 & 20 & 18 & 23.94 \\
\hline married & 37 & 74 & 20 & 80 & 57 & 75.81 \\
\hline \multicolumn{7}{|l|}{ Family size } \\
\hline$\leq 6$ & 31 & 62 & 16 & 64 & 47 & 62.51 \\
\hline$>6$ & 19 & 38 & 14 & 56 & 33 & 43.89 \\
\hline \multicolumn{7}{|l|}{ Occupation } \\
\hline Employed & 42 & 84 & 21 & 84 & 63 & 83.79 \\
\hline Unemployed & 8 & 16 & 4 & 16 & 12 & 15.96 \\
\hline \multicolumn{7}{|l|}{ Literacy } \\
\hline Literate & 39 & 78 & 19 & 76 & 58 & 77.14 \\
\hline Illiterate & 11 & 22 & 6 & 24 & 17 & 22.61 \\
\hline \multicolumn{7}{|l|}{ Residence } \\
\hline Rural & 42 & 84 & 22 & 88 & 64 & 85.12 \\
\hline Urban & 8 & 16 & 3 & 12 & 11 & 14.63 \\
\hline
\end{tabular}


Table.2 Comparison of the characteristics of MDR-TB and control cases

\begin{tabular}{|c|c|c|c|c|c|}
\hline Group & & MDR TB & Non MDR TB & OR $(95 \% \mathrm{CI})$ & p-value \\
\hline History of Prior Tuberculosis & $\begin{array}{l}\text { Yes } \\
\text { No }\end{array}$ & $\begin{array}{l}47 \\
3 \\
\end{array}$ & $\begin{array}{c}0 \\
25\end{array}$ & $\begin{array}{c}692.1429 \\
(34.3891-13930.6417)\end{array}$ & $<0.0001 *$ \\
\hline $\begin{array}{l}\text { Smoking } \\
\text { N=30 (MDR TB) } \\
\text { N=19 (non MDR TB) }\end{array}$ & $\begin{array}{l}\text { Yes } \\
\text { No }\end{array}$ & 19 & 9 & $\begin{array}{c}4.7273 \\
(1.1751-19,0168)\end{array}$ & $0.0287 *$ \\
\hline $\begin{array}{l}\text { Alcoholism } \\
\text { N=30 (MDR TB) } \\
\text { N=19 (non MDR TB) }\end{array}$ & $\begin{array}{l}\text { Yes } \\
\text { No }\end{array}$ & 19 & $\begin{array}{l}9 \\
10\end{array}$ & $\begin{array}{c}3.4286 \\
(1.0304-11.4078)\end{array}$ & $0.0445 *$ \\
\hline Diabetes Mellitus & $\begin{array}{l}\text { Yes } \\
\text { No }\end{array}$ & $\begin{array}{r}15 \\
35 \\
\end{array}$ & $\begin{array}{r}7 \\
18\end{array}$ & $\begin{array}{c}1.1020 \\
(0.3810-3.1876)\end{array}$ & 0.8577 \\
\hline Distance & $\begin{array}{l}\text { Yes } \\
\text { No }\end{array}$ & $\begin{array}{l}35 \\
15\end{array}$ & $\begin{array}{l}15 \\
10\end{array}$ & $\begin{array}{c}1.1556 \\
(0.5705-4.2414)\end{array}$ & 0.3879 \\
\hline Side Effects & $\begin{array}{l}\text { Yes } \\
\text { No }\end{array}$ & 22 & 25 & $\begin{array}{c}40.2632 \\
(2.3221-698.1242) \\
\end{array}$ & $<0.0001 *$ \\
\hline Migration & $\begin{array}{l}\text { Yes } \\
\text { No }\end{array}$ & 29 & 15 & $\begin{array}{c}1.086 \\
(0.409-2.887) \\
\end{array}$ & 0.868 \\
\hline Social stigma & $\begin{array}{r}\text { Yes } \\
\text { No }\end{array}$ & 27 & $\begin{array}{l}72.1801 \\
18 \\
\end{array}$ & $(0.7448-6.3818)$ & 0.1550 \\
\hline $\begin{array}{l}\text { Knowledge on MDR TB } \\
\text { and DOTS PLUS } \\
0.0362 *\end{array}$ & Yes & 31 & 92.9006 & (1.0708-7.8572) & \\
\hline $\begin{array}{l}\text { History of contact } \\
\text { with TB }\end{array}$ & $\begin{array}{l}\text { Yes } \\
\text { No }\end{array}$ & $\begin{array}{r}5 \\
35\end{array}$ & 23 & $\begin{array}{c}1.6429 \\
(0.2935-9.1946)\end{array}$ & 0.5721 \\
\hline
\end{tabular}

The study predominantly discussed about two factors like non-compliance and risk factors for the development of MDR TB. The fact that the distance of the health care centre from patient's home and non- adherence to treatment is not significant in the present study ( $\mathrm{p}$ value $=0.3879$ ). Travel-related factors were major determinants of non-adherence among the newly diagnosed patients. This study found strong association between the side effects and the discontinuation of treatment (OR: 40.2632 (2.3221-698.1242); p value $=<0.0001)$. Side effects of the drugs given in the DOTS like Vomiting, Drowsiness, and Loss of appetite are one of the major factors for non-compliance of the 
patients a study from Bihar and West Bengal reported that intolerance to drugs accounted $20 \%$ of drop out cases (Chattergee et al., 2003). In another study in Pakistan done by Khan et al., factors, side effects of drugs in $13 \%$ cases, was the attributed cause of discontinuation of treatment (Khan et al., 2004). Drug related factors like adverse drug reaction and toxicity contributed the highest role in non-compliance of tuberculosis.

The present study found that some degree of association between the improvement of symptoms and discontinuation of treatment. It is noted that the patient take the drugs for first one month properly as scheduled. Then he feels that his symptoms get improved and so he discontinues his treatment thinking that his disease is cured. A study from Bihar and West Bengal reported that improvement in symptoms as reason for $40 \%$ drop outs (Chattergee et al., 2003). This study did not find strong association between the migration and non-compliance. Occupation of the patient and its related migration contributes to the discontinuation of the treatment. The inability to work due to treatment side effects, the relationship between financial constraints and having adequate nutrition, and the threat of job loss were all intertwined factors that present challenges for patients to complete treatment (O'Boyle et al., 2000).

It is easy to understand that those with poor education, low income, and small living space are more susceptible to TB, because infectious disease and poverty often go hand in hand. Lack of access to the health facility to pick up medications due to distance to the facility could lead to poor adherence to treatment (Gopi et al., 2007). There was the association between having an alcohol drinking habit and having MDR TB. Most interviewed patients themselves did not note alcohol addiction as a factor for not adhering to treatment but alcohol abuse was expressed as a major barrier to treatment adherence noted by their providers and attenders. In a multivariable analysis, alcohol consumption during treatment was found to be the strongest predictors of poor treatment outcome for MDR TB (Fleming et al., 2006).

Literacy of the community plays a great role in the development of MDR TB. Kaona et al., in their study on assessment of factors contributing to $\mathrm{TB}$ treatment adherence in Ndola, Zambia showed that feeling well was the major reason for patient stopping treatment (Kaona et al., 2004). Educational status had a positive impact on adherence. Possible explanations for such findings include, as the level of education increases, the understandings about the importance of adherence to treatment increases. But we did not find any significance between literacy and the compliance.

Majority of patients in the present study belonged to the older age group (more than 30 years), of which 32 cases were than 50 yrs. of age group. The risk of MDR-TB has been seen to be higher among elderly individuals (age $>45$ years) by Kimerling and colleagues (Kimerling et al., 2003). Of the 50 MDR TB cases 30 cases $(60 \%)$ were males and 20 cases (40\%) were females. Of the 25 controls 19 (76\%) were males and 6 (24\%) were females. Gender difference was not found to be a significant risk factor for the development of drug resistance in the present study. Studies in Western Europe and the Samara region of Russia revealed that males had a significantly higher risk of MDR-TB (Ruddy et al., 2005).

In the current study, association between social stigma and having MDR TB was high with OR 2.1801 (95\% CI 0.7448-6.3818) $(\mathrm{p}=0.1550)$, though not significant. Social stigma and lack of scientific awareness about the disease and social commitments are stated reasons for interrupting and defaulting $\mathrm{TB}$ 
treatment. This study revealed that previous treatment of tuberculosis was strongly associated with MDR TB; OR =692.1429 (95 $\%$ CI 34.3891-13930.6417) $(\mathrm{p}=<0.0001)$. The prevalence of drug resistance in previously treated cases was higher than new cases for each drug alone as well as for all six drugs, as reported previously (Zhao et al., 2012; Yu et al., 2010; Shao et al., 2011). This suggests that retreatment is deficient and poses a threat to continued transmission, which has not yet manifested itself among new patients although three of the MDR patients failed to reveal the previous treatment particulars.

The present study revealed that the association between having a history of smoking and MDR TB was significant with OR 4.7273 and 95\%CI ranging from 1.175119, 0168 ( $\mathrm{p}=0.027)$. We found smoking to be positively associated with non-adherence, and hence to drug resistance amongst the MDR TB patients. Cigarette smoking had been shown to be associated with interruption with treatment similar to findings in Turkey and India although the mechanism is not well understood (Balbay et al., 2005; Bagchi et al., 2010). This study had no significant association between Diabetes and TB (OR 1.120 and CI ranging from 0.3810-3.1876, p value $=0.8577)$. There is growing evidence that Diabetes mellitus is an important risk factor for TB and might affect disease presentation and treatment response (Dooley and Chaisson, 2009; Alisjahbana et al., 2007).

Tuberculosis remains an important problem in Human immunodeficiency virus (HIV) infected patients worldwide. In the present study none of the cases and controls had HIV infection, hence it was unable to assess the significance of HIV as a risk factor. Literature suggests that, appropriate management of HIV-associated TB remains extremely challenging due to diagnostic difficulties, adherence concerns, the overlapping drug side effects, drug-drug interactions, and the occurrence of immune reconstitution inflammatory syndrome. Concomitant treatment also leads to a higher pill burden this may lead to poorer adherence among these patients. Poor adherence to anti-TB drugs can lead to an increased risk of drug resistance, including multi-drug and extensively drug resistant $\mathrm{TB}$, which is difficult to treat and contribute to increased mortality (Padmapriyadarsini, 2011). But we could not suggest anything related to this issue since all the patients in our study are non-HIV patients.

Smoking and alcoholism are major risk factor and determinant of non-compliance to treatment respectively, in the treatment of MDR TB. Though these two factors are modifiable by the patient himself, this study highlights other two important factors- Side effects of the treatment and previous TB exposure as a determinant of non-compliance and the latter a potential risk factor for developing MDR TB. Unfortunately these two factors are non-modifiable. Thereby, this study concludes that the patients on DOTS plus treatment for MDR TB, due to the side effects of drugs and the previous TB exposure, have a risk of developing further drug resistance.

\section{Acknowledgement}

The authors are gratefully acknowledged The Dean, Tirunelveli Medical College Hospital, Tirunelveli, Tamil Nadu and The Staff of Microbiology and Thoracic Medicine of Tirunelveli Medical College Hospital.

\section{References}

Alisjahbana, B., Sahiratmadja, E., Nelwan, E.J., Purwa, A.M., Ahmad, Y., Ottenhoff, T.H., et al., (2007). The Effect of Type 2 Diabetes Mellitus on 
the Presentation and Treatment Response of Pulmonary Tuberculosis. Clinical Infectious Diseases, 45, 428435.

Bagchi S, Ambe G, Sathiakumar N. (2010). Determinants of Poor Adherence to Anti-Tuberculosis Treatment in Mumbai, India. Int J Prev Med, 1 (4): 223-232.

Balbay O, Annakaya AN, Arbak PBilgin C and Erbas M. (2005). Which patient are able to adhere to Tuberculosis treatment: A study in rural area in the North west part of Turkey. Jpn J Infect Dis, 58 (3): 152-158.

Chattergee P, Benerjee B, Dutt D, Pati RR, Mullick A. (2003). A Comparative Evaluation of Factors and Reasons for Defaulting in Tuberculosis Treatment in the States of West Bengal, Jharkhand and Arunachal Pradesh. Indian J Tuberc, 50:17-21.

Dooley, K. and Chaisson, R. (2009). Tuberculosis and Diabetes Mellitus: Convergence of Two Epidemics. The Lancet Infectious Diseases, 9, 737-746.

Fleming MF, Krupitsky E, Tsoy M Zvartau E, Brazhenko N, Jakubowiak W et al. (2006). Alcohol and drug use disorders, HIV status and drug resistance in a sample of Russian TB patients Int J Tuberc Lung Dis, 10:565-70.

Gandhi NR, Moll A, Sturm AW, Pawinski R, Govender T, et al., (2006). Extensively drug-resistant tuberculosis as a cause of death in patients co-infected with tuberculosis and HIV in a rural area of South Africa. Lancet 368: 1575-1580.

Gopi PG, Vasantha M, Muniyandi M, Chandrasekaran V, Balasubramanian R, et al., (2007) Risk factors for nonadherence to directly observed treatment (DOT) in a rural tuberculosis unit, South India. Indian J Tuberc 54: 66-70.
Kaona FAD, Tuba M, Siziya S, and Sikaona L. (2004). An assessment of factors contributing to treatment adherence and knowledge of TB transmission among patients on TB treatment. BMC Public Health. 4: 68.

Khan SU, Awan SR, Shabir I, Iqbal R. (2004). Non Compliance to Treatment in Tuberculous Patients. Pak J Chest Med. 10: 31-34.

Kimerling ME, Slavuckij A, Chavers S, Peremtin GG, Tonkel T, Sirotkina O, et al., (2003). The risk of MDR-TB and polyresistant tuberculosis among the civilian population of Tomsk city, Siberia. Int J Tuberc Lung Dis, 7:86672.

O'Boyle SJ, Power JJ, Ibrahim MY. (2000). Factors affecting patient compliance with anti-tuberculosis chemotherapy using the directly observed treatment, Short Course Strategy (DOTS). Int J Tuberc Lung Dis 6: 307-12.

Padmapriyadarsini C, Narendran G, Swaminathan S (2011). Diagnosis and treatment of tuberculosis in HIV coinfected patients. Indian J Med Res 134: 850-865.

Ruddy M, Balabanova Y, Graham C, Fedorin I, Malomanova N, Elisarova E, et al., (2005). Rates of drug resistance and risk factor analysis in civilian and prison patients with tuberculosis in Samara region, Russia. Thorax, 60:130-5.

Shao Y, Yang D, Xu W, Lu W, Song H, Dai Y, Shen H, Wang J. (2011). Epidemiology of anti-tuberculosis drug resistance in a Chinese population: current situation and challenges ahead. BMC Public Health, 11:110.

Sharma SK. Multi drug resistant tuberculosis. Indian J Med Res 2004; 4:76.5.

Songhua C, Pengcheng H, Xiaomeng W, Jieming Z, Xinting W, Kai W.2013 Risk factors for multidrug resistance among previously treated patients with 
tuberculosis in eastern China: a casecontrol study. International Journal of Infectious Diseases. 17(12): 1116-1120.

WHO Report M/XDR TB: Multi-drug and extensively drug-resistant tuberculosis2010 Global report on surveillance and response. Geneva: World Health Organization; 2010.

World Health Organisation. (2006). The Stop TB Strategy. Building on and enhancing DOTS to meet the TB-related Millennium Development Goals. Geneva: WHO press.

World Health Organization. Anti-tuberculosis drug resistance in the world: fourth global report. Geneva: WHO; 2008.
World Health Organization: The Global Plan to Stop TB 2011-2015. Geneva: World Health Organization; 2011.

Yu CC, Chang CY, Liu CE, Shih LF, Hsiao JH, Chen CH. (2010). Drug resistance pattern of Mycobacterium tuberculosis complex at a Medical Centre in Central Taiwan, 2003-2007. J Microbiol Immunol Infect, 43(4): 285-290.

Zhao Y, Xu S, Wang L, Chin DP, Wang S, Jiang G, Xia H. et al., (2012). National survey of drug-resistant tuberculosis in China. N Engl J Med, 366 (23): 21612170.

\section{How to cite this article:}

Amudha, V.P., G. Sucilathangam, N. Dilip Jaivanth and Revathy, C. 2018. Assessment of Risk Factors in MDR TB Patients. The Reasons behind Their Admission to DOTS plus Centres. Will They Pass Through? Int.J.Curr.Microbiol.App.Sci. 7(10): 1775-1784. doi: https://doi.org/10.20546/ijcmas.2018.710.202 